\title{
Inclusão do farelo grosso de trigo na dieta e seu efeito sobre as propriedades físicas e sensoriais da carne caprina
}

\author{
Inclusion of coarse wheat bran in the diet and its effect on physical and sensorial properties of goat meat
}

\author{
Argélia Maria Araújo DIAS ${ }^{1 \star}$, Maria Inês Sucupira MACIEL ${ }^{2}$, Ângela Maria Vieira BATISTA ${ }^{3}$, \\ Francisco Fernando Ramos de CARVALHO ${ }^{3}$, Adriana GUIM ${ }^{3}$, Gilvan SILVA ${ }^{4}$
}

\begin{abstract}
Resumo
Avaliou-se o efeito de diferentes níveis de inclusão do Farelo Grosso de Trigo (FGT) (0,0;8,9; 19,8 e 31,7\%) na dieta sobre os atributos sensoriais (aroma caprino, aroma estranho, cor, textura, maciez, sabor caprino, suculência e aparência geral) e nas qualidades físico-químicas (pH e perdas de líquido no cozimento e cor da carne), operando no sistema CIE - $\mathrm{L}^{*}, \mathrm{a}^{\star} \mathrm{e} \mathrm{b}^{*}$ de lombos caprinos em delineamento inteiramente casualizado (4 tratamentos e 4 repetições). A inclusão do FGT não influenciou o aroma da carne, no entanto, houve efeito significativo para a cor da carne e sabor característico caprino. A textura, maciez e aparência geral foram decrescentes. O pH foi quadrático com ponto de máxima de $18,53 \%$ e o percentual médio de perdas no cozimento foi de $25,5 \%$. Nos parâmetros de cor a luminosidade $\left(L^{*}\right)$ teve efeito linear decrescente variando de 30,2 a 32,2; a cor vermelha ( $\mathrm{a}^{\star}$ ) foi intensificada variando de 7,56 a 8,47 com aumento dos níveis, enquanto a cor amarela $\left(b^{*}\right)$ apresentou equação quadrática com ponto de máxima de $14,53 \%$. A inclusão de níveis crescentes de FGT na dieta animal alterou todos os atributos da carne caprina, exceto o aroma. De acordo com a avaliação cromática, a coloração da carne caprina apresentou-se mais escura com níveis mais elevados de FGT.
\end{abstract}

Palavras-chave: subprodutos; maciez; sabor; textura.

\begin{abstract}
The effect of inclusion levels of Coarse Wheat Bran (CWB) (0; 8.9; 19.8 and 31.7\%) in the animal diet on sensorial attributes (goat aroma, strange aroma, color, texture, tenderness, goat flavor, juiciness and general appearance) and physical-chemical characteristics ( $\mathrm{pH}$, losses during cooking and color of the meat operating in the $\mathrm{CIE}\left(\mathrm{L}^{*}, \mathrm{a}^{*} \mathrm{e} \mathrm{b}^{*}\right)$ system of goat loins were evaluated. A statistical design of four treatments and four replications was used. The inclusion of CWB did not significantly affect goat meat aroma. However, there was a quadratic effect on color and on the characteristic taste of the meat. Texture, tenderness and general appearance decreased linearly. For $\mathrm{pH}$, the behavior was quadratic, with a maximum of $18.53 \%$ and the average percentage of losses during cooking was $25.5 \%$. There was a decreasing linear effect on brightness $\left(\mathrm{L}^{*}\right)$, which varied from 30.2 to 32.2 ; red color $\left(\mathrm{a}^{*}\right)$ was intensified with the increase of CWB levels, and varied from 7.56 to 8.47 , while yellow color $\left(\mathrm{b}^{\star}\right)$ showed a quadratic behavior (maximum of $14.53 \%$ ). The increasing inclusion of CWB in the animal diet affected all sensorial attributes, except for aroma. According to the chromatic evaluation, goat meat color was darker with increasing CWB levels.

Keywords: by-products; tenderness; taste; texture.
\end{abstract}

\section{Introdução}

A carne caprina vem se sobressaindo ao longo das últimas décadas como uma das opções dentre as carnes vermelhas, seja por seu valor nutricional, seja por suas qualidades organolépticas (MADRUGA, 2003). As vantagens comparativas, em termos nutricionais, da carne caprina relativamente às demais carnes consumidas no mercado, estão relacionadas aos baixos teores de gordura e colesterol, baixa caloria e alta digestibilidade, além de elevados níveis de proteína e ferro (CARLUCCI et al., 1998; MADRUGA et al., 1999b). Essas características justificam sua procura nos dias atuais, uma vez que os consumidores estão cada vez mais conscientes da influência do consumo dos alimentos na preservação de sua saúde.

O valor comercial da carne está baseado em seu grau de aceitabilidade, o qual está diretamente correlacionado aos parâmetros de palatabilidade do produto. As características da carne que contribuem com a palatabilidade são aquelas agradáveis aos olhos, nariz e paladar, dentre as quais sobressaem os aspectos organolépticos de sabor ou flavour e de suculência (MADRUGA et al., 2005).

Recebido para publicação em 25/1/2007

Aceito para publicação em 8/5/2008 (002236)

1 Universidade Federal Rural de Pernambuco - UFRPE, Rua Aurora Caçote, 555, Vila Cardeal e Silva Areias, CEP 50870-490, Recife - PE, Brasil,

E-mail: argeliadias@oi.com.br

2 Departamento de Ciências Domésticas, Universidade Federal Rural de Pernambuco - UFRPE, Rua Dom Manoel de Medeiros, s/n, Dois Irmãos, CEP 52171-900,

Recife-PE, Brasil, E-mail: m.ines@dcd.ufrpe.br

${ }^{3}$ Conselho Nacional de Desenvolvimento Científico e Tecnológico - CNPq, Departamento de Zootecnia, Universidade Federal Rural de Pernambuco - UFRPE,

Rua Dom Manoel de Medeiros, s/n, Dois Irmãos, CEP 52171-900, Recife - PE, Brasil, E-mail: abatista@dz.ufrpe.br; ffrcarva@dz.ufrpe.br; aguim@dz.ufrpe.br

${ }^{4}$ Departamento de Zootecnia, Universidade Federal Rural de Pernambuco - UFRPE, Rua Dr. Vilas Boas, 208, Areias, CEP 50780-640, Recife - PE, Brasil,

E-mail: gilvanzootec@ig.com.br

${ }^{*}$ A quem a correspondência deve ser enviada 
Os alimentos são avaliados primeiro pela visão (forma, aspecto e cor), depois pelo olfato (odor) e, em algumas situações pelo tato. A impressão causada por essas sensações predispõe ao seu consumo. Na mastigação o sentido do tato informa sobre sua textura. E do gosto, sobre seu sabor. Portanto, a sensação agradável ou desagradável que provoca a aceitação ou a recusa de um alimento é o resultado da combinação de todos os estímulos captados pelos cinco sentidos (ORDÓNEZ, 2005).

A cor é um atributo de importância fundamental no julgamento da qualidade, uma vez que seu estímulo atinge precisamente o sentido da visão, decisivo na escolha e aceitação de um alimento. Os pigmentos da carne estão formados em sua maior parte por proteína; a hemoglobina que é o pigmento sanguíneo e a mioglobina que é o pigmento muscular que constitui 80 a $90 \%$ dos pigmentos totais. Deficiências nutricionais na alimentação animal refletem nos teores da mioglobina. Como exemplo, dietas pobres em ferro originam concentrações de mioglobina muito baixas (LAWRIE, 2005). Dentre os espaços de cores desenvolvidos com o intuito de se obter a caracterização objetiva da cor, a Commission Internationale de I' Èclairage (CIE), em 1976 (CIE, 1978), especificou o sistema CIELAB $\left(L^{*}, \mathrm{a}^{*}\right.$ e b ${ }^{*}$ ), no qual a cor particular tem uma única localização, especificada numericamente em um espaço tridimensional esférico, definido por três eixos perpendiculares; o eixo $L^{\star}$ (luminosidade); o eixo $a^{*}$ e o eixo $b^{*}$. Quando aplicada a cor da carne, pode-se afirmar que valores mais baixos de $\mathrm{L}^{\star} \mathrm{e}$ maior de $\mathrm{a}^{\star}$ apresentam cores mais vermelhas (SIMÕES; RICARDO, 2000).

As carnes de caprino e ovino podem, eventualmente, apresentar características sensoriais desejáveis, como sabor e aroma mais intensos que aqueles característicos da espécie. Esse fato tem sido associado a diversos fatores como alimentação, idade, condições fisiológicas, castração e estresse dos animais antes do abate. No entanto, a verdadeira causa do problema ainda não está bem esclarecida (ZAPATA et al., 2003). É influenciada por fatores pré-abate que podem ser intrínsecos à espécie, à raça, à individualidade, ao grau de exercício dos animais, ao estresse, às condições ambientais e à composição da dieta.

Os fatores pós-abate que incidem sobre a qualidade da carne se referem ao acondicionamento das carcaças, condição de passagem pelo rigor mortis, maturação da carne, técnicas de preservação e forma de cozimento da mesma (ZAPATA et al., 2003). A qualidade da carne é uma combinação dos atributos sabor, suculência, textura, maciez e aparência, associados a uma carcaça com pouca gordura, muito músculo e preços acessíveis (SILVA SOBRINHO, 2001). No entanto, a pesquisa tem demonstrado que a concentração de gordura presente na carne é indicativo de qualidade da carne relacionado ao melhor sabor e maciez.

No semi-árido nordestino, a alimentação dos animais é fator limitante da produção de carne caprina. Devido às estiagens prolongadas ao longo do ano, quando fica reduzida a oferta de forragens, o que incide negativamente no desempenho animal. Nesse contexto, o confinamento pode ser uma alternativa viável, principalmente quando se pretende intensificar o sistema de produção e melhorar a oferta de carne de qualidade.
Em busca de alternativas alimentares, têm-se pesquisado ao longo desses anos a utilização de alimentos alternativos na alimentação animal, principalmente visando minimizar os custos de produção e, mais recentemente, avaliar os possíveis fatores que possam alterar a qualidade da carne caprina. Apesar da carne caprina ser muito consumida na região Nordeste do país, alguns trabalhos avaliam sua qualidade com enfoque maior para o efeito do peso ao abate e castração (BEZERRA et al., 2004; MADRUGA; ARRUDA, 2000; MADRUGA et al., 2002), sexo (TADORO, 2002), genótipo (DHANDA et al., 2003) e sistema de criação (JOHNSON; McGOWAN, 1998). Vale salientar que, em geral, nessas pesquisas como o objetivo não é avaliar o aspecto nutricional utiliza-se o milho na ração animal como alimento convencional e tem-se obtido carne caprina como alimento de excelente valor nutricional e características sensoriais.

No processo de obtenção da farinha de trigo, o grão inicialmente é quebrado e passa por subseqüentes peneiras em etapas repetidas, onde se obtêm separadamente os resíduos denominados de "farelo grosso", "farelo fino", "remoído escuro" e "remoído claro", que são separados durante o processamento. Porém, para a comercialização esses resíduos são misturados, constituindo então o farelo de trigo tradicional, que é largamente utilizado nas rações animais. O conhecimento das características nutricionais deste co-produto, bem como dos seus constituintes, poderá agregar-lhe valor se sua comercialização for feita separadamente e não na forma do tradicional farelo de trigo.

O uso de subprodutos agroindustriais na alimentação animal é uma alternativa viável, tendo em vista que muitos desses alimentos poderão substituir, mesmo em parte, alimentos convencionais. Comparativamente ao milho, o Farelo Grosso de Trigo (FGT) possui mais proteína e fibra em detergente neutro em sua composição (DIAS et al., 2005), portanto sua utilização poderá baratear o custo da ração e reduzir os distúrbios ruminais causados por alimentos ricos em amido, como o milho.

Embora a alimentação seja preponderante na determinação das características sensoriais da carne (SIQUEIRA; ROÇA, 2002), há poucos dados disponíveis na literatura consultada sobre o efeito da utilização de alimentos alternativos sobre os aspectos sensoriais da carne caprina.

Assim sendo, o objetivo desse trabalho foi avaliar o efeito da inclusão do farelo grosso de trigo, em substituição ao milho, sobre as propriedades físicas e atributos sensoriais da carne caprina.

\section{Material e métodos}

\subsection{Material}

Foram utilizados vinte e quatro cabritos mestiços, machos não castrados, com peso vivo inicial de $20 \mathrm{~kg}$ e idade entre 6 e 7 meses.

Após um período de 18 horas de jejum de sólidos e líquidos, os animais foram pesados e abatidos. Ao abate os animais foram insensibilizados por atordoamento, seguido por sangria através da seção das carótidas e jugulares e esfola. As carcaças foram encaminhadas à câmara frigorífica, onde permaneceram por 24 horas a $4{ }^{\circ} \mathrm{C}$. Após esse período, as carcaças foram seccionadas ao meio, e da meia carcaça esquerda foram obtidos os cortes comerciais 
(perna, lombo, costelas, paleta e pescoço). Os lombos foram imediatamente embalados em sacos plásticos a vácuo, previamente identificados, e armazenados a $-20{ }^{\circ} \mathrm{C}$ durante 150 dias.

As rações experimentais foram constituídas por feno de capim-Tifton-85 (Cynodon dactylon, (L.) Pers), moído em máquina forrageira, milho moído, farelo de soja, farelo grosso de trigo e mistura mineral, com $50 \%$ de volumoso e $50 \%$ de concentrado (Tabela 1), ofertados em mistura completa. Os percentuais de farelo grosso $(0,0 ; 8,9 ; 19,8 ; 31,7 \%)$ foram incluídos na ração objetivando padronizar dados de desempenho animal, visando principalmente facilitar a comparação de resultados de pesquisas, como também facilitar no balanceamento da ração animal.

\subsection{Preparo das amostras}

Para realização das análises físico-químicas e sensoriais da carne caprina, foram utilizados dezesseis lombos, sendo quatro de cada tratamento. Esses foram retirados do freezer e descongelados em refrigeração a $4{ }^{\circ} \mathrm{C}$ durante um período de 18 horas, em seguida foram desossados para obtenção dos músculos longissimus dorsis. (MADRUGA; ARRUDA, 2000).

\subsection{Caracterização cromática da carne caprina}

A caracterização cromática foi realizada no músculo longissimus dorsis, após dissecação e exposição ao ar (sob refrigeração a $5{ }^{\circ} \mathrm{C}$ ), por 30 minutos, para permitir a oxige- nação superficial da mioglobina. Utilizou-se um colorímetro Minolta Color reader CR-400 com modo de reflectância, utilizando iluminação difusa, iluminante $\mathrm{C}$ (tipo de fonte de luz que representa a média da luz de dia, com temperatura de cor de $6740^{\circ} \mathrm{K}$ ) e os ângulos de $0^{\circ}$ e de $2^{\circ}$, referentes aos ângulos de detecção e do observador, respectivamente, operando no sistema CIE $\left(L^{*}, a^{*} e b^{*}\right)$, sendo $L^{*}$ a luminosidade, $a^{*} a$ intensidade da cor vermelha e $b^{\star}$ a intensidade da cor amarela. Foram aferidas três medições em diferentes pontos do músculo anotando-se os valores médios, segundo metodologia relatada por Abularach et al. (1998).

\subsection{Determinação do pH e umidade da carne}

Amostras de $10 \mathrm{~g}$ foram coletadas em vários pontos de cada músculo, de acordo com cada tratamento, e trituradas. Desse material, foram pesados $5 \mathrm{~g}$ que foram diluídos em $100 \mathrm{~mL}$ de água destilada a $25^{\circ} \mathrm{C}$, e a mistura agitada até que as partículas ficassem uniformemente suspensas, então, executou-se a leitura com auxílio de um medidor de $\mathrm{pH}$ digital (Digimed, modelo DMPH-2, São Paulo) combinado com um eletrodo de vidro (Analyser, modelo $2^{\text {a }}$ 09E, São Paulo).

A determinação de umidade foi realizada após pesar $10 \mathrm{~g}$ de amostra homogeneizada e introduzida em placa de petri. Em seguida, a amostra foi colocada em estufa a $105^{\circ} \mathrm{C}$ por 24 horas e posteriormente pesada.

Tabela 1. Composição percentual e química das dietas e dos ingredientes da ração (\% MS).

\begin{tabular}{|c|c|c|c|c|}
\hline \multirow[t]{2}{*}{ Ingredientes } & \multicolumn{4}{|c|}{ Níveis de inclusão do farelo grosso } \\
\hline & 0,0 & 8,9 & 19,8 & 31,7 \\
\hline Feno de tifton & 50 & 50 & 50 & 50 \\
\hline Milho & 25,2 & 18,1 & 9,7 & 0,0 \\
\hline Farelo grosso de trigo & 0 & 8,9 & 19,8 & 31,7 \\
\hline Farelo de soja & 23,8 & 22,0 & 19,5 & 17,3 \\
\hline Sal mineral & 0,5 & 0,5 & 0,5 & 0,5 \\
\hline Calcário & 0,5 & 0,5 & 0,5 & 0,5 \\
\hline \multicolumn{5}{|l|}{ Composição química da ração (\%) } \\
\hline Matéria Seca (MS) & 85,4 & 85,5 & 85,7 & 85,8 \\
\hline Matéria Orgânica (MO) & 93,6 & 93,3 & 92,4 & 92,5 \\
\hline Proteína Bruta $(\mathrm{PB})$ & 19,5 & 19,3 & 19,1 & 19,0 \\
\hline Extrato Etéreo (EE) & 2,3 & 2,3 & 2,2 & 2,2 \\
\hline Fibra em Detergente Neutro (FDN) & 46,0 & 48,9 & 52,6 & 56,5 \\
\hline Fibra em Detergente Neutro corrigido para proteína $\left(\mathrm{FDN}_{\mathrm{p}}\right)$ & 43,6 & 46,1 & 49,3 & 52,7 \\
\hline Fibra em detergente ácido & 22,9 & 23,8 & 24,8 & 25,9 \\
\hline Carboidratos totais & 71,9 & 71,7 & 71,6 & 71,3 \\
\hline Carboidratos não fibrosos & 28,3 & 25,5 & 22,3 & 18,6 \\
\hline Nutrientes Digestíveis Totais (NDT) & 66,3 & 64,9 & 63,2 & 61,3 \\
\hline Composição química dos ingredientes & Feno de tifton & Milho & $\mathrm{FGT}^{1^{*}}$ & Farelo de soja \\
\hline $\mathrm{MS}^{1}$ & 85,74 & 84,31 & 85,59 & 85,52 \\
\hline $\mathrm{MO}^{2}$ & 92,61 & 98,41 & 93,68 & 92,44 \\
\hline $\mathrm{PB}^{3}$ & 9,05 & 9,55 & 16,95 & 52,64 \\
\hline $\mathrm{EE}^{4}$ & 1,72 & 4,15 & 3,48 & 1,53 \\
\hline $\mathrm{FDN}^{5}$ & 77,50 & 15,24 & 48,15 & 14,48 \\
\hline $\mathrm{FDN}_{\mathrm{P}}$ & 73,40 & 15,20 & 43,48 & 12,71 \\
\hline $\mathrm{MM}^{7}$ & 7,39 & 1,59 & 6,32 & 7,56 \\
\hline $\mathrm{NDT}^{8}$ & 51,60 & 87,85 & 69,73 & 77,2 \\
\hline
\end{tabular}

Perfil granulométrico com 46,4\% > 1,70 mm; e Farelo grosso de trigo. 


\subsection{Análise sensorial}

Após a leitura do músculo inteiro no colorímetro foram padronizadas amostras de $150 \mathrm{~g}$ de cada músculo, pesadas e cortadas em cubos de $2,5 \mathrm{~cm}^{3}$. As amostras foram envolvidas em papel alumínio e assadas em forno pré-aquecido a $200{ }^{\circ} \mathrm{C}$. Com auxílio de termômetros introduzidos no centro das amostras, que eram retirados até que a temperatura interna atingisse $75{ }^{\circ} \mathrm{C}$. Em seguida, quatro cubos escolhidos ao acaso foram transferidos para um béquer pré-aquecido, codificado e coberto para evitar perdas de substâncias voláteis. $\mathrm{O}$ béquer contendo cada amostra foi mantido sob aquecimento $\left(65\right.$ a $\left.75^{\circ} \mathrm{C}\right)$ até o momento de ser ofertado aos provadores do painel sensorial (MADRUGA; ARRUDA, 2000).

A análise sensorial foi realizada contando com a participação de nove provadores treinados. Esses provadores foram selecionados, entre trinta pessoas, após ter sido testada sua sensibilidade aos sabores: ácido, amargo, azedo e doce. Em seguida, passaram por mais cinco sessões nas quais foram trabalhados os atributos da carne caprina demonstrados no Tabela 2.

Estes atributos foram avaliados através do teste descritivo, utilizando-se o método de Análise Descritiva Quantitativa (ADQ), em uma escala não estruturada de $9 \mathrm{~cm}$ e com intensidade dos atributos variando de 1 (menor intensidade) a 9 (maior intensidade) como descrito por Ferreira et al. (2000).

Nas cabines individuais foram disponibilizadas, para cada provador, amostras de todos os tratamentos, servidas em pratos e garfos descartáveis de polietileno de cor branca. Para remover o sabor residual entre as amostras, utilizou-se água mineral em temperatura ambiente e bolachas sem sal.

As fichas contendo todos os atributos foram entregues aos provadores conforme demonstrado no Tabela 3. Foi solicitado que, após degustarem cada amostra, assinalassem o ponto na escala que melhor refletisse o seu julgamento da intensidade do atributo, fazendo um traço vertical na escala e escrevendo o código da amostra. Posteriormente, todos os dados foram transformados em notas variando de 1 a 9 .
Com a mesma equipe de provadores treinados e as mesmas amostras, foi realizado o teste de diferença, utilizando-se o método de comparação múltipla para o atributo de sabor da carne caprina. Neste caso, foi utilizada a luz vermelha para evitar interferências da cor e a metodologia descrita por Chaves (2001). Em todas as análises sensoriais foram utilizadas três seções para cada provador.

\subsection{Perdas de líquido no cozimento}

O material utilizado para avaliar as perdas na cocção foram os mesmos lombos utilizados na análise sensorial, que foram pesados, cortados e embrulhados em papel alumínio com registros antes e após serem assados em forno pré-aquecido a $200{ }^{\circ} \mathrm{C}$, por aproximadamente 20 minutos. $\mathrm{O}$ excesso de líquido retido no papel alumínio foi desprezado para cada amostra. As determinações das perdas pela cocção foram realizadas pela diferença de peso das amostras antes e depois da cocção e expressas em porcentagem.

\subsection{Análises estatísticas}

As análises estatísticas das variáveis estudadas foram submetidas às análises de variância e regressão, em função dos níveis de inclusão do farelo grosso de trigo nas dietas, utilizando-se o programa Estatístico SAS (1999).

Tabela 3. Escala de avaliação dos atributos utilizados na análise sensorial.

\begin{tabular}{llr}
\hline \multicolumn{1}{c}{ Atributos } & \multicolumn{2}{c}{ Escala } \\
\hline Aroma característico "caprino" & Fraco & Forte \\
\cline { 2 - 3 } Aroma estranho & Forte & Fraco \\
\cline { 2 - 3 } Cor & Escura & Clara \\
\cline { 2 - 3 } Textura & Péssima & Boa \\
\cline { 2 - 3 } Maciez & Macia & Dura \\
Sabor característico "caprino" & Péssimo & Muito bom \\
\cline { 2 - 3 } Sabor estranho & Nenhum & Forte \\
Suculência & Nenhuma & Buculenta \\
Aparência geral & Ruim & Boa \\
\hline
\end{tabular}

Tabela 2. Atributos utilizados na análise sensorial.

\begin{tabular}{|c|c|}
\hline Atributos & Descrição \\
\hline \multicolumn{2}{|l|}{$\Rightarrow$ Aroma } \\
\hline Característico & Odor típico de carne caprina \\
\hline Estranho & Odor não característico \\
\hline$\Rightarrow$ Cor & Sensação produzida pela estimulação da retina pelos raios luminosos de comprimentos de onda variável \\
\hline Escura & Cor característica da carne de animais mais velhos \\
\hline Clara & Cor característica da carne de animais mais jovens \\
\hline$\Rightarrow$ Textura & Propriedades reológicas e estruturais da carne perceptíveis pelos receptores mecânicos e táteis \\
\hline$\Rightarrow$ Maciez & Propriedades de resistência da carne à primeira mordida \\
\hline$\Rightarrow$ Sabor característico caprino (flavour) & Sabor típico de carne caprina \\
\hline Estranho & Sabor não característico da carne caprina \\
\hline$\Rightarrow$ Suculência & Propriedade de textura em relação à percepção da qualidade de umidade absorvida ou liberada pela carne \\
\hline \multicolumn{2}{|l|}{$\Rightarrow$ Aparência geral } \\
\hline Boa & Propriedades visíveis da carne como cor, forma e brilho característico da carne caprina \\
\hline Ruim & Aparência desagradável como cor atípica e textura dura, seca e firme \\
\hline
\end{tabular}




\section{Resultados e discussão}

A cor apresentada pela carne depende, fundamentalmente, da quantidade total e do tipo de mioglobina presente (ORDÓNEZ, 2005), e a quantidade total de mioglobina depende de vários fatores, dentre os quais se podem destacar: a espécie, $\mathrm{o}$ sexo, a idade, o manejo, o tipo de músculo e a porção analisada, e o tipo de dieta.

Consta na Tabela 4 o resultado da avaliação cromática das amostras de carne caprina utilizando-se o sistema CIE $\left(\mathrm{L}^{*}, \mathrm{a}^{*} \mathrm{e} \mathrm{b}^{\star}\right)$ dos músculos Longíssimos dorsis. Observou-se decréscimo linear $(\mathrm{p}<0,05)$ no índice de luminosidade $\left(\mathrm{L}^{*}\right)$ em função do aumento de FGT, indicando redução do grau de luminosidade à medida que a carne tornou-se mais escura. A intensidade da cor vermelha $\left(a^{*}\right)$ aumentou linearmente, enquanto a cor amarela teve efeito quadrático da inclusão de FGT na dieta, com ponto de máxima de $14,53 \%$. A coloração da carne caprina mais avermelhada com maior concentração de mioglobina está relacionada com o nível de Fe nos tecidos (CHAVES, 2001; ZAPATA et al., 1995). Como não foi possível determinar a concentração de ferro no tecido, não podemos inferir que o aumento do FGT nas dietas possa ter contribuído para teores elevados de mioglobina no tecido muscular e possa ter proporcionado o maior escurecimento do músculo. Assim, maiores investigações precisam ser realizadas nas próximas pesquisas dessa natureza.

$\mathrm{O}$ pH final da carne influencia na textura, na cor e no perfil microbiológico (HULTIN, 1993). Como nessa pesquisa o valor de pH (Tabela 4) foi mensurado na amostra do músculo após período de estocagem, correlações mais precisas com a qualidade da carne ficam difíceis, entretanto, é importante como parâmetro para sua avaliação no momento em que foi oferecido à equipe de provadores. Observa-se que, apesar do efeito quadrático com ponto de máxima de 18,53\% de nível de inclusão do farelo grosso de trigo, os valores médios foram muitos próximos para justificar uma maior ou menor acidez na carne. Vale salientar que os valores médios encontrados estão de acordo aos relatados por Dhanda et al. (1999) numa faixa de 5,6-5,8 e (MARINOVA, 2001) com 5,5-5,8 para a carne caprina.

A perda de líquido no cozimento é uma importante característica de qualidade, associada ao rendimento da carne no momento do consumo (PARDI et al., 1993). Nesse experimento não foram verificadas diferenças de perdas de líquido no cozimento entre os tratamentos, cuja média de peso foi de $25,5 \%$.
Esses valores encontrados estão na faixa dos resultados citados por Dhanda et al. (2003), que avaliaram parâmetros de qualidade de carne caprina de diferentes genótipos. Concordando com os resultados da perda de líquido, também não houve diferença significativa no teor de umidade da carne com valor médio de 73,12 g.100 $\mathrm{g}^{-1}$

Nos atributos sensoriais não houve diferença quanto aos seguintes aspectos organolépticos: aroma da carne caprina, aroma estranho, sabor estranho e suculência da carne. No entanto, cor da carne, sabor característico caprino, textura, maciez e aparência geral foram influenciados pelos níveis de inclusão do FGT (Figura 1).

A cor da carne caprina foi avaliada pelos provadores (Figura 1) e a melhor pontuação para esse atributo $(7,7)$ foi obtida na inclusão de $8,9 \%$ de FGT. Observou-se que níveis crescentes do resíduo resultaram em menor aceitação da carne. Possivelmente o fato de a carne apresentar uma cor mais escura (vermelho mais intenso), como observada anteriormente na avaliação cromática da carne, tenha proporcionado menor aceitação pelos provadores. Geralmente, o consumidor de carne caprina

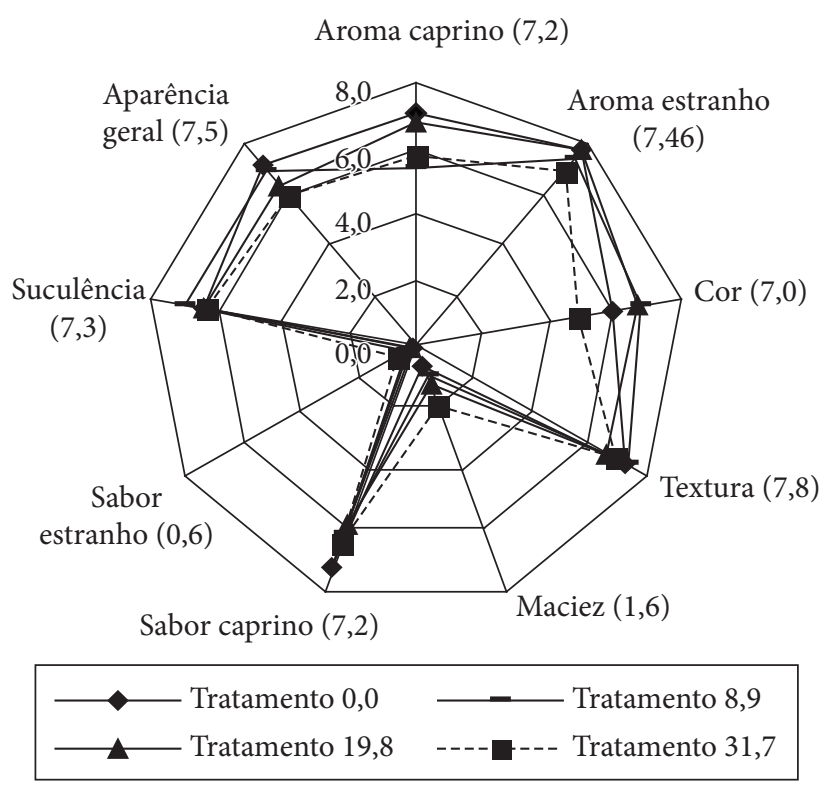

Figura 1. Atributos sensoriais da carne caprina em função dos níveis de inclusão do farelo grosso de trigo.

Tabela 4. Parâmetros de cor $\left(\mathrm{L}^{\star}, \mathrm{a}^{\star}, \mathrm{b}^{\star}\right)$, valores de $\mathrm{pH}$, umidade e perdas de líquido no cozimento (PC) da carne caprina em função do nível de inclusão de farelo grosso de trigo.

\begin{tabular}{|c|c|c|c|c|c|c|c|}
\hline \multirow[t]{2}{*}{ Variáveis } & \multicolumn{4}{|c|}{ Níveis de inclusão (\%) farelo grosso de trigo } & \multirow[t]{2}{*}{$\mathrm{CV}(\%)$} & \multirow[t]{2}{*}{ Equação de regressão } & \multirow[t]{2}{*}{$\mathrm{r}^{2}$} \\
\hline & 0,0 & 8,9 & 19,8 & 31,7 & & & \\
\hline \multicolumn{8}{|l|}{ Parâmetros de cor } \\
\hline $\mathrm{L}^{\star}$ (luminosidade) & 32,2 & 32,4 & 31,3 & 30,2 & 7,0 & $\hat{Y}=32,570-0,0679 x$ & 0,85 \\
\hline $\mathrm{b}^{*}($ amarelo $)$ & 5,33 & 6,37 & 6,14 & 5,01 & 15,0 & $\hat{Y}=5,3752+0,1368 X-0,0047 X^{2}$ & 0,84 \\
\hline $\mathrm{pH}$ & 5,85 & 5,73 & 5,57 & 5,75 & 1,1 & $\hat{Y}=5,8663-0,0277 X+0,0007 X^{2}$ & 0,72 \\
\hline
\end{tabular}


prefere carne mais clara (ARRUDA, 2003), pois associa a cor escura à procedência de carne de animal mais velho.

Como a cor é atributo determinante na escolha do alimento, provavelmente o efeito negativo na aparência geral da carne com aumento do FGT, além de outros fatores, possa ser atribuído à coloração mais escura da carne.

Observa-se que houve efeito decrescente na textura da carne para os níveis 0,0, 8,9, 19,8 e 31,7\% de inclusão de FGT. Esse efeito negativo pode ser conseqüência de um maior consumo de fibras pelos animais alimentados com FGT, em relação à energia, à medida que o FGT era incluído na dieta, de acordo com relatado por Dias et al. (2005) e constatado na concentração da ração fornecida (Tabela 1). Possivelmente, esse menor aporte energético dos animais tenha contribuído para redução da atividade física muscular, e alterado proporções dos tecidos (muscular, adiposo, ósseo) refletindo, assim, na formação de estrutura diferenciada do tecido muscular, como, por exemplo, tecido muscular com textura mais rígida, o que contribuiu em menor aceitação da carne por parte dos provadores, quando FGT foi incluído nos níveis mais altos da dieta.

Estudos sobre aceitação de consumidores indicam que a maciez da carne é freqüentemente o atributo mais importante na satisfação geral do consumidor (LAWRIE, 2005). A maciez da carne, conforme demonstrado na escala presente no Tabela 3, teve efeito decrescente, partindo de pontuação de carne macia com 0,69 à dura com 2,79, com inclusão de FGT, ou seja, quanto maior o nível de inclusão do FGT na dieta mais dura a carne. Possivelmente, a menor concentração de gordura subcutânea encontrada na perna de caprinos com níveis crescentes de FGT, relatada por Dias et al. (2005), tenha contribuído para reduzir a maciez da carne. Existe uma relação direta entre a menor concentração de gordura na carcaça e o menor grau de maciez na carne (SILVA SOBRINHO, 2001). Enquanto Siqueira, Simões e Fernandes (2001) demonstraram que a gordura subcutânea tem participação na maciez da carne ao atuar como isolante, evitando o resfriamento brusco da carcaça, que produz encurtamento dos sarcômeros e promove maior dureza da carne.

Quanto à suculência da carne, apesar dos valores estarem muito próximos (Figura 1), quando avaliada a correlação de Person entre esse atributo e a textura foi obtido valor elevado $(r=0,82)$, conforme Tabela 5. Em termos de valores absolutos, as menores pontuações foram obtidas com níveis crescentes de FGT, variando de 7,87 a 6,78. Apesar de não ter sido realizada análise de gordura nessa pesquisa (lombo), quando determinada a composição tecidual da perna caprina foi relatado por Dias et al. (2006), a partir de material proveniente da mesma carcaça, que houve uma redução na quantidade de gordura subcutânea e intermuscular na perna caprina nos tratamentos com a inclusão do FGT. Esse mesmo cenário foi observado visivelmente durante manuseio do material para preparo das análises sensoriais, o que possivelmente pode ter influenciado negativamente na suculência da carne.

Tabela 5. Correlações de Person entre os atributos suculência e textura da carne caprina.

\begin{tabular}{ccccc}
\hline Variável & Variável & Observações & Correlação & Significância \\
\hline Suculência & Textura & 32 & 0,82903 & 0,0003 \\
\hline
\end{tabular}

A inclusão de níveis crescentes de FGT não alterou o atributo de aroma caprino. Como ocorreram modificações no sabor da carne caprina, esperava-se que o aroma caprino também fosse alterado. Segundo Wong et al. (1975), certos ácidos graxos com cadeias ramificadas com grupo metil, presentes na gordura subcutânea dos caprinos, seriam os componentes diretamente responsáveis pelo odor caprino, e confirmariam esta hipótese através de análise sensorial, na qual o odor caprino foi relacionado com a presença do ácido 4-metil octanóico. Possivelmente, a quantidade de ácidos graxos ramificados presentes no músculo longissimus dorsis, proveniente da inclusão do FGT na dieta, não tenha sido suficiente para alterar o aroma caprino. Apesar de ter contribuído para obter sabor de carne caprina diferenciada.

Avaliando o sabor da carne caprina pelo método de Análise Descritiva Qualitativa (ADQ) foram observadas alterações no sabor da carne com inclusão do FGT (Figura 1) e, com menor pontuação $(5,72)$, para dieta com $31,7 \%$ de inclusão de FGT. Acredita-se que essas alterações no sabor da carne sejam resultado de um conjunto de sensações gustativas (suculência, maciez e textura), olfativa (aroma) e táteis percebidas durante a degustação. A identificação e a quantificação do perfil de ácidos graxos presentes na carne é importante porque a presença de uma maior quantidade de gorduras saturadas solidifica após cozimento e influencia a palatabilidade da carne (MADRUGA; ARRUDA, 2000). Assim, fica difícil atribuir alteração a fator específico, sem ter realizado outras análises complementares.

A avaliação do atributo de sabor da carne caprina também foi analisada através do teste de diferença, utilizando-se o método de comparação múltipla (Figura 2). Tomando como referência uma amostra R (com 0\% de inclusão de FGT) em relação aos diferentes níveis de inclusão de FGT na dieta. Esse resultado demonstrou que, quanto maior o nível de inclusão do FGT na dieta animal, menor o sabor característico da carne caprina, ou seja, a inclusão do FGT reduziu o sabor característico da carne.

Não houve alteração quanto ao sabor estranho na carne, o que é esperado quando cuidados especiais são aplicados

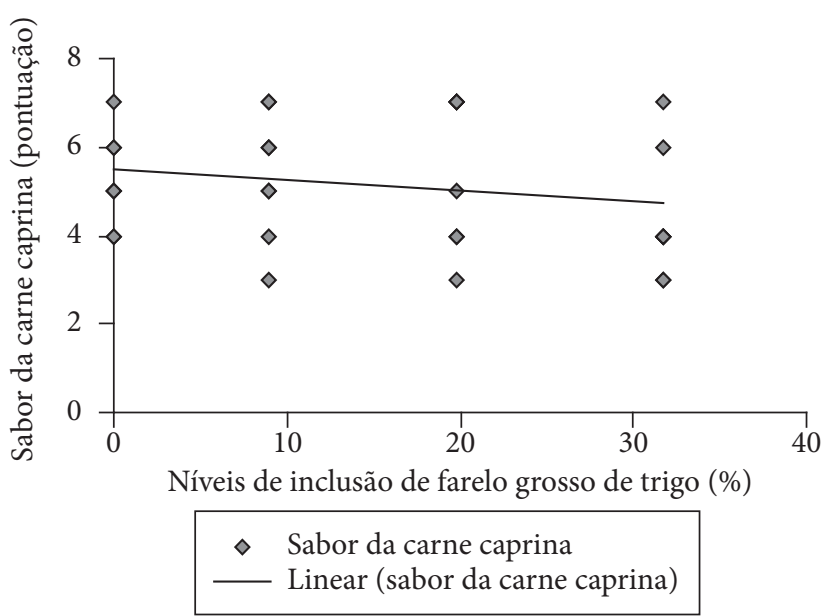

Figura 2. Análise de comparação múltipla tomando como referência uma amostra R ( $0 \%$ de inclusão FGT) para o atributo sabor da carne caprina em função dos níveis de inclusão do farelo grosso de trigo. 
durante preparo das amostras. Enquanto que a aparência geral da carne foi reduzida com inclusão de FGT. Embora outros fatores possam ter contribuído, a coloração escura da carne foi determinante na decisão dos provadores.

\section{Conclusões}

A inclusão de níveis crescentes de farelo grosso de trigo na dieta animal alterou todos os atributos da carne caprina, exceto o aroma. Na avaliação cromática a cor tornou-se mais escura.

\section{Referências bibliográficas}

ABULARACH, M. L. S.; ROCHA, C. E.; FELÍCIO, P. E. Características de qualidade do contrafilé de touros jovens da raça nelore. Revista Ciência e Tecnologia de Alimento, v. 18, n. 2, p. 205-210, 1998.

ARRUDA, S. G. B. Perfil de ácidos graxos e qualidade da carne de caprinos da raça saanen inteiros e castrados com diferentes pesos ao abate. Pernambuco, 2003.167p. Tese - (Doutorado em Nutrição), Universidade Federal de Pernambuco.

BEZERRA, F. J. et al. Effect of age at slaughter on chemical composition of meat from Moxotó goats and their crosses. Small ruminant research, v. 55, n. 1, p. 177-181, 2004.

CARLUCCI, A. et al. Sensory evaluation of young goat meat. Meat Science, v. 50, n. 1, p. 131-136, 1998.

CHAVES, J. B. P. Métodos de diferença em avaliação sensorial de alimentos e bebidas. Viçosa: Universidade Federal de Viçosa, 2001. 91p.:il. (Cadernos didáticos, 33).

CIE - COMISSION INTERNATIONALE DE I' ECLAIRAGE. Recommendations on uniform color spaces-color difference equations, psychomettic color terms. Paris: CIE, 1978. Supplement n. 2 to CIE Publication n. 15.

DIAS, A. M. A. et al. Substituição do milho pelo farelo grosso de trigo na alimentação de caprinos. Consumo e digestibilidade. In: JORNADA DE ENSINO, PESQUISA E EXTENSÃO, 5, 2005, Recife, PE. Anais... Recife, PE: Universidade Federal Rural de Pernambuco, 2005. CD-ROM.

DIAS, A. M. A. Utilização do farelo grosso de trigo na alimentação de caprino. Recife, 2006. 120p. Tese - (Doutorado em Zootecnia), Universidade Federal Rural de Pernambuco.

DHANDA, J. S. et al. The influence of goat genotype on the production of capretto and chevon carcasses. 2. Meat quality. Meat Science, v. 52, n. 4, p. 363-367, 1999.

DHANDA, J. S.; TAYLOR, D. G.; MURRAY, P. J. Growth, carcass and meat quality parameters of male goat: effects of genotype and liveweight at slaughter. Small Ruminant Research, v. 50, n. 1-2, p. 57-66, 2003.

FERREIRA, V. L. P. F. et al. Analise sensorial testes descritivos e afetivos. Campinas, SP: SBCTA, 2000. 127p. (Manual técnico: Série Qualidade).

JOHNSON, D. D.; McGOWAN, C. H. Diet management effects on carcass atributes and meat quality of young goats. Small Ruminant Research, v. 28, p. 93-98, 1998.

HULTIN, H. O. Características Del tecido muscular. In: FENEMA, O. R. Química de los alimentos. Zaragoza: Acribia, 1993. p. 515-888.

LAWRIE, R. A. Ciência da carne. 6 ed. Porto Alegre: Artmed, 2005.

MADRUGA, M. S.; ARRUDA, S. G. B.; NASCIMENTO, J. A. Castration and slaughter age affects on nutritive value of the mestiço goat meat. Meat Science, v. 52, n. 2, p. 119-125, 1999a.
MADRUGA, M. S.; ARRUDA, S. G. B.; NASCIMENTO, J. A. Castration and slaughter age effects on nutritive value of the "mestiço" goat meat. Meat Science, v. 52, n. 2, p. 119-125, 1999 b.

MADRUGA, M. S.; ARRUDA, S. G. B. A. Efeito da castração sobre parâmetros químicos, físico-químicos e sensoriais da carne caprina de animais mestiços. Revista Ciência e Tecnologia de Alimentos, v. 20, n. 1, p. 23-26, 2000.

MADRUGA, M. S. et al. Influencia da idade de abate e da castração nas qualidades físico-químicas, sensoriais e aromáticas da carne caprina. Revista Brasileira de Zootecnia, v. 31, n. 3, p. 1562-1570, 2002.

MADRUGA, M. S. Fatores que afetam a qualidade da carne caprina e ovina. In: SINCORTE - SIMPÓSIO INTERNACIONAL DE CAPRINOS E OVINOS DE CORTE, 2, 2003, João Pessoa - PE. Anais... João Pessoa - PE: EMEPA, p. 417-432, 2003.

MADRUGA, M. S. et al. Qualidade da carne de cordeiros santa Inês terminados com diferentes dietas. Revista Brasileira de Zootecnia, v. 34, n. 1, p. 309-315, 2005.

MARINOVA, P. et al. Carcass composition and meat quality of kids fed sunflower oil supplemented diet. Small Ruminant Research, v. 42, n. 3, p. 219-227, 2001.

ORDÓNEZ, J. A. Tecnologia de alimentos de origem animal. Porto Alegre: Artmed, 2005. v. 2, p. 280.

PARDI, M. C. et al. Ciência higiene e tecnologia da carne: Tecnologia da sua obtenção e transformação. Goiânia: Centro Editorial e Gráfico Universidade de Goiás, 1993. 586p.

SAS - STATISTICAL ANALYSIS SYSTEMS. User" guide. Versão 8.0. North Carolina, 1999.

SILVA SOBRINHO, A. G. Criação de ovinos. Jaboticabal: Funep, 2001. 302p.

SIMÕES, J. A.; RICARDO, R. Avaliação da cor da carne tomando como referencia o músculo rectus abdominis, em carcaças de cordeiros leves. Revista Portuguesa de Ciências Veterinárias, v. 95, n. 535, p. 124-127, 2000.

SIQUEIRA, E. R.; SIMÕES, C. D.; FERNANDES, S. Efeito do sexo e do peso ao abate sobre a produção de carne de cordeiros. Morfometria da carcaça, peso dos cortes, composição tecidual e componentes não constituintes da carcaça. Revista Brasileira de Zootecnia, v. 30, n. 4, p. 1299-1307, 2001

SIQUEIRA, E. R.; ROÇA, R. O. A. Características sensoriais da carne de cordeiros das raças hampshire down, santa inês e mestiços bergmácia $\mathrm{x}$ corriedale abatidos com quatro distintos pesos. Revista Brasileira de Zootecnia, v. 31, n. 3, p. 1269-1272, 2002.

TADORO, M. et al. The influence of age at slaughter and litter size on some quality traits of kid meat. Small Ruminant Research, v. 44, n. 1, p. 75-80, 2002.

WONG, E.; NIXON, L. N.; JOHNSON, C. B. Volatile medium chain fatty acids and mutton flavor. Journal of Agriculture Food Chemistry, v. 23, p. 495-498, 1975.

ZAPATA, J. F. F. et al. Carcass tissue distribution and composition of the lean meta from kids fe dan iron supplemented diet. International Congress of Meat Science and Technology, 41, 1995, San Antonio, Texas, USA. Proceedings... v. 2, p. 40-41. San Antonio, Texas, USA, p. 20-25, 1995.

ZAPATA, J. F. F; NOGUEIRA, C. M.; SEABRA, L. M. J. Características da carne de pequenos ruminantes do Nordeste do Brasil. Boletim Sociedade Brasileira de Ciência e Tecnologia de Alimentos, Campinas, v. 37, n. 2, p. 146-153, 2003. 